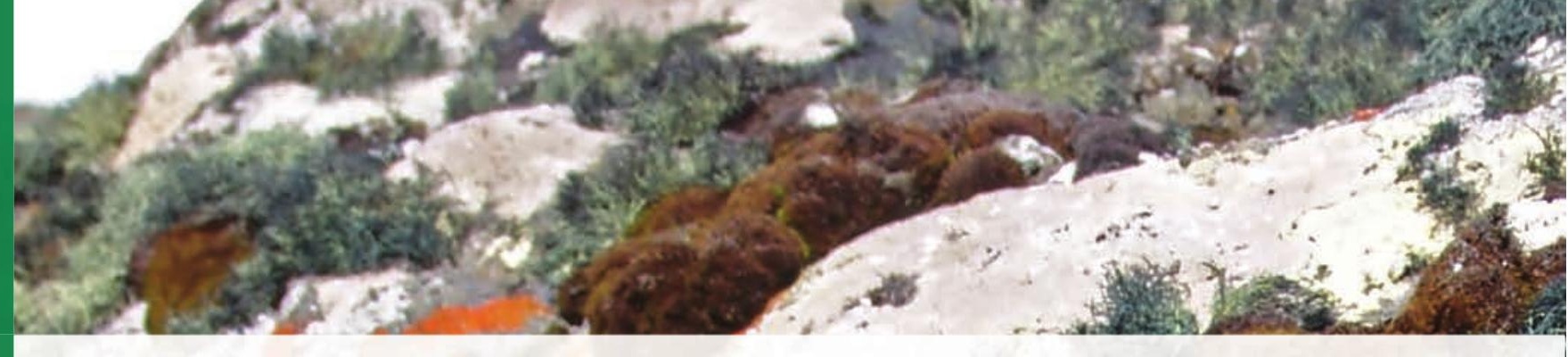

\title{
DISTRIBUTION AND ABUNDANCE OF ANTARCTIC AND SUBANTARCTIC SEABIRDS WITHIN AN OFFSHORE TRANSECT BETWEEN RIO GRANDE/RS AND RIO DE JANEIRO/RJ
}

\author{
Gabriel Vieira Vier*, Júlia Victória Grohmann Finger \& Maria Virginia Petry \\ Universidade do Vale do Rio dos Sinos - UNISINOS. Laboratório de Ornitologia e Animais Marinhos \\ Av. Unisinos, n 950, Cristo Rei, 93022-000, São Leopoldo, Rio Grande do Sul, Brazil. \\ *e-mail: gabrielvier@hotmail.com \\ https://doi.org/10.4322/apa.2016.009
}

\begin{abstract}
In this study, we aimed to analyze the distribution and abundance of subantarctic and Antarctic seabirds along the offshore route between Rio Grande (RS) and Rio de Janeiro (RJ). Three surveys were performed during April in 2011, 2012 and 2013. On board censuses were conducted to evaluate the abundance and distribution of seabirds. The most abundant species was the Atlantic yellow-nosed albatross Thalassarche chlororhynchos, with 51 individuals and the least species abundant was the Blackbellied Storm Petrel Fregetta tropica, with only two individuals. Latitude $29^{\circ} S$ showed the largest abundance of seabirds ( $n=41$ ), whereas the smallest abundance was observed at latitude $24^{\circ} S(n=2)$. The highest richness was observed at latitudes $26^{\circ} S$ and $30^{\circ} \mathrm{S}$ ( $n=5$ in each degree). We conclude that most birds that use the Brazilian coast as a foraging area are actually south migrant species and that further studies are necessary to assess factors which may explain the distribution of these birds.
\end{abstract}

Keywords: Atlantic Ocean, Latitudinal Variation, Brazilian Coast

\section{Introduction}

Most seabirds found along the Brazilian coast breed in the Antarctic and subantarctic regions and remain along the coastal sites in search for food during their migratory period (Vooren \& Fernandes, 1989). The distribution of seabirds at sea is influenced by several biotic and abiotic factors, such as productivity, hydrography, fisheries, and distance from the colony (Garthe, 1997; Weichler et al., 2004; Krüger \& Petry, 2011). On the east coast of South America, the meeting of the Malvinas Ocean Current with the Brazilian Current causes a phytoplankton bloom that attracts nektonic fauna foraged by seabirds (Jehl, 1974; Veit \& Braun, 1984; Orgeira, 1995;). Therefore, this high productivity stimulates the presence of many bird species in this area. There are 38 south migrant species occurring over the continental shelf waters off Brazil mainly during the austral winter period, most of them belonging to the order Procellariiformes composed of albatrosses and petrels
(Costa et al, 2011). Individuals belonging to this order show long lifespan and high reproductive rate (Furness \& Monaghan, 1987). Several species nest only every two years, though longer gaps between reproduction attempts are common (Warham, 1996). These characteristics, alongside with mortality in by catch of long-line fisheries, make populations of Procellariiformes highly vulnerable (Neves \& Olmos, 1998).

The order Procellariiformes is extremely important to biodiversity maintenance and as top predators; they can provide information on ecosystem changes. Hence, analyzing their distribution outside their reproductive area is of great importance. Therefore, the aim of this study was to analyze the distribution and abundance of subantarctic and Antarctic seabirds along the offshore route between the cities of Rio Grande (Rio Grande do Sul state) and Rio de Janeiro (Rio de Janeiro state), Brazil. 


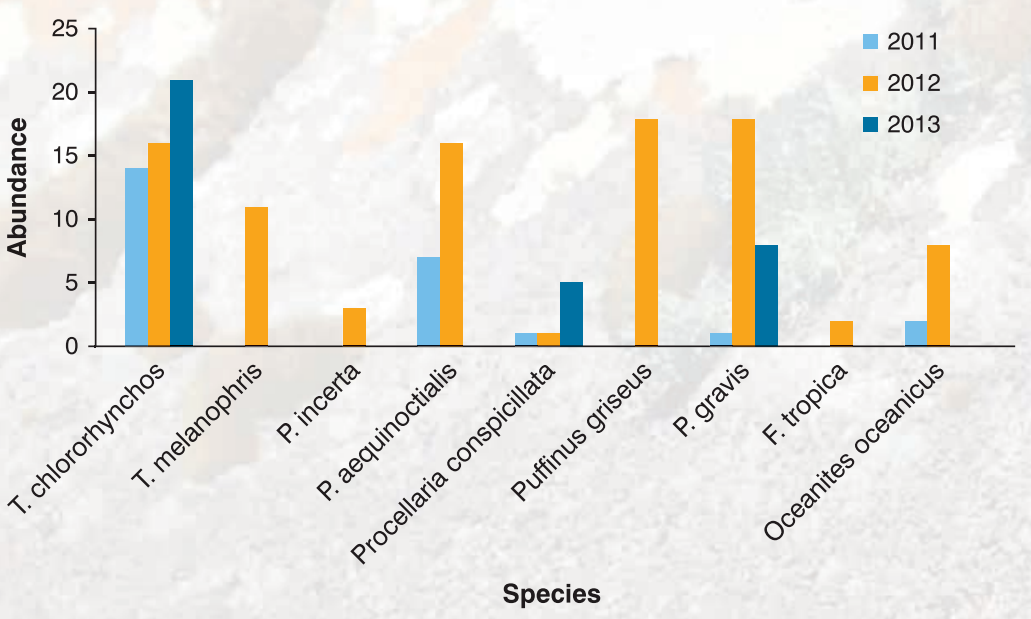

Figure 2. Species abundance according to each sampled year.

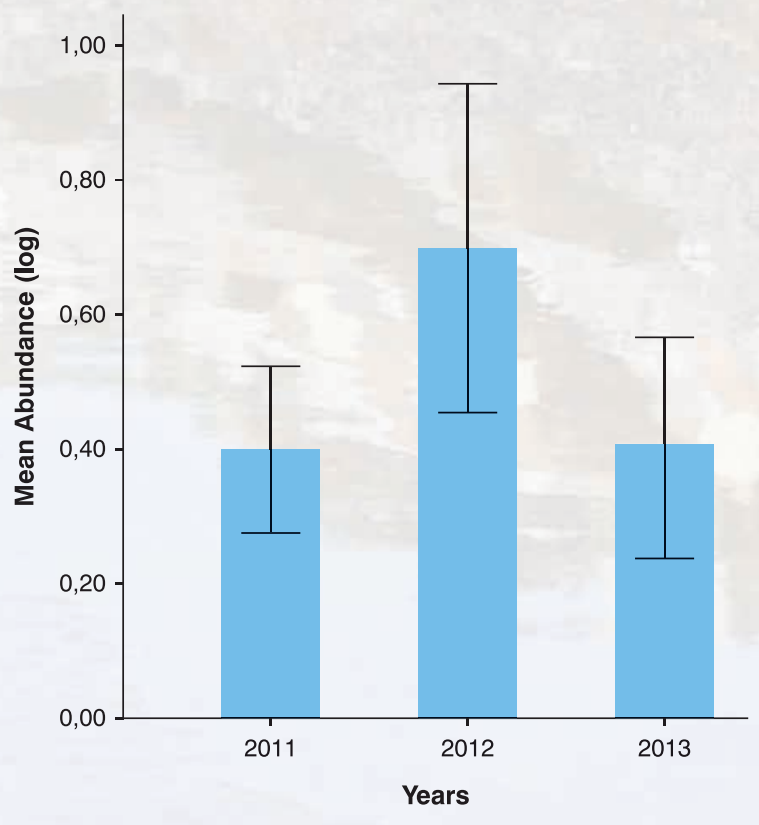

Error bars: $95 \% \mathrm{Cl}$

Figure 3. Mean abundance according to the sampled years.

3.92\%. All five remaining species showed abundance of less than 18 individuals each (Figure 2). Significant difference was observed between the relative abundance in the sampled years ( $p=0.025$ and $\mathrm{F}=4.107$ ) (Figure 3 ).

Latitude $29^{\circ} \mathrm{S}$ showed the largest abundance of seabirds with 41 individuals, although the highest richness was observed at latitudes $26^{\circ} \mathrm{S}$ e $30^{\circ} \mathrm{S}$, with five species in each degree. The lowest abundance was observed at latitude $24^{\circ} \mathrm{S}$, with only two individuals of two species.

\section{Discussion}

All seabirds observed in this survey were out of their breeding season (Harrison, 1983). Their movements are influenced by productivity and they tend to forage over greater areas of open ocean than while in chick attendance period. Antarctic and subantarctic species are also related to deeper water (P. gravis), higher atmospheric pressures, lower sea surface temperatures, and greater wind speed (Thalassarche sp.) (Krüger \& Petry, 2011). This might explain the greater richness at latitudes $26^{\circ} \mathrm{S}$ and $30^{\circ} \mathrm{S}$, which present greater depth than others. Latitudes $29^{\circ} \mathrm{S}$, $26^{\circ} \mathrm{S}$, and $30^{\circ} \mathrm{S}$ might have had a higher abundance and richness, respectively, because they were the most sampled ones. The large abundance of the Atlantic yellow-nosed albatross could be explained by its formal distribution. This species breeds on the South Atlantic, but disperse to the Southern Ocean, mainly west to South America, and is very common at latitudes $23^{\circ} \mathrm{S}-45^{\circ} \mathrm{S}$. T. chlororhynchos presented low frequency of occurrence (FO $<4.00 \%$ ) in the Indian Ocean (Péron et al., 2010), whereas in the Atlantic Ocean, on the Brazilian coast, high frequency of occurrence $(\mathrm{FO}=58.82 \%)$ was found for this species. The differences in abundance of some species between the sampled years might be explained by variations in the distance of the observers 
